\title{
Reactivity of Recycled Glass Powder in a Cementitious Medium
}

\section{Monique Tohoue Tognonvi', Arezki Tagnit-Hamou², Léon Koffi Konan³, Ablam Zidol2, Wilfried Cyrille N'Cho ${ }^{3}$}

\author{
${ }^{1}$ Department of Biological Sciences, University of Peleforo-Gbon-Coulibaly, Korhogo, Côte d'Ivoire \\ ${ }^{2}$ Department of Civil Engineering, University of Sherbrooke, Quebec, Canada \\ ${ }^{3}$ Laboratory of Chemistry of Inorganic Materials, University of Felix Houphouet-Boigny, Abidjan, Côte d'Ivoire \\ Email: Monique.tognonvi@gmail.com
}

How to cite this paper: Tognonvi, M.T. Tagnit-Hamou, A., Konan, L.K., Zidol, A. and N'Cho, W.C. (2020) Reactivity of Recycled Glass Powder in a Cementitious Medium. New Journal of Glass and Ceramics, 10, 29-44.

https://doi.org/10.4236/njgc.2020.103003

Received: April 14, 2020

Accepted: June 6, 2020

Published: June 9, 2020

Copyright $(\odot 2020$ by author(s) and Scientific Research Publishing Inc. This work is licensed under the Creative Commons Attribution International License (CC BY 4.0).

http://creativecommons.org/licenses/by/4.0/

\begin{abstract}
The reactivity of the recycled glass powder (GP) in a cementitious medium has been studied over time by means of X-ray diffraction and thermal gravimetric analysis. Two different mixtures based on cement/glass powder ( 0 or $20 \mathrm{wt} \%$ GP) and lime/glass powder (70 wt\% GP) were considered. Analysis revealed the coexistence of both hydration and pozzolanic reaction during the hardening of the mortars. At young age, the cement hydration would prevail over the pozzolanic one resulting in a decrease of physico-chemical and mechanical properties of the material due to the dilution effect. The pozzolanic reaction that predominates from 91 days, would induce the formation of supplementary C-S-H leading to improve the material properties.
\end{abstract}

\section{Keywords}

Glass Powder, Pozzolanic Reaction, Calcium Silicate Hydrate, Thermal Analysis, X-Ray Diffraction

\section{Introduction}

Bottle glasses, essentially composed of amorphous $\mathrm{SiO}_{2}, \mathrm{Na}_{2} \mathrm{O}$ and $\mathrm{CaO}$, are stable non-biodegradable materials. Residues of mixed glass (mixture of several colors) that are difficult to dispose are found in landfills and constitute a major environmental issue. Recycling them into building materials arouses a lot of interest and is the subject of numerous studies [1] [2] [3] [4]. They can be used as aggregates in mortars or architectural concrete [5] [6] [7].

The durability of these structures is affected by the alkali-aggregate reaction (AAR) favored by the high alkali content in this material [5]. However, it has 
been shown that reducing the size of the glass particles (less than $80 \mu \mathrm{m}$ ) helps to control and decrease the expansion due to AAR [8] [9] [10]. The high amorphous silica content of the glass powder provides interesting pozzolanic properties similar to those of conventional cement additions, for example the fly ash [1] [11] [12]. In general, a significant contribution from the pozzolanic properties of the glass powder is notable from 56 days with mechanical properties almost similar to that of concrete which contains only cement [3].

Recent work has shown that the glass powder has the ability to significantly improve the resistance to penetrability of chloride ions, thereby increasing the durability of concrete [13]. According to these studies, the decrease in the penetrability of chloride ions results from the refining of pores and grains, and even more from the pozzolanic reaction of additions [13].

Unlike the hydration of the cement which has been the subject of several studies [14] [15] [16], that of cementitious additions, in particular glass powder, remains less known. This work aims to study the hydration reaction of the glass powder in the presence of hydrated lime or cement through structural (XRD) and thermal (TGA-DSC) characterization of the prepared mixtures. In addition, the properties in the fresh and hardened state of mortars containing glass powder as a partial replacement for cement were evaluated to demonstrate the effectiveness of the pozzolanic activity of glass powder in construction materials. This study enables to better understand the physicochemical mechanism of the glass powder reactivity in concrete resulting in the optimum management of such residues in building materials.

\section{Materials and Methods}

\subsection{Materials}

Waste mixed glasses collected by a sorting center (Tricentris, Quebec-Canada) were crushed using a ball mill in 6 sequences of $25 \mathrm{~min}$. The obtained glass powder possesses amorphous structure (Figure 1(a)) and is mainly composed of silicon oxide (72\%), sodium oxide (13\%) and calcium oxide (11\%) (Table 1). The cement used is an ordinary Portland cement (OPC) provided by HOLCIM company. The mean diameter of GP particles is D50 $=17 \mu \mathrm{m}$ whereas the one of the cement is $15 \mu \mathrm{m}$.

Table 1. Physical properties of OPC and GP.

\begin{tabular}{cccc}
\hline \multirow{2}{*}{ Characteristics } & \multicolumn{3}{c}{ Materials } \\
\cline { 2 - 4 } & & GP & OPC \\
\hline Density & & 2.57 & 3.15 \\
Blaine fineness $\left(\mathrm{m}^{2} / \mathrm{kg}\right)$ & $\mathrm{D} 10$ & 437 & 414 \\
& $\mathrm{D} 50$ & 17 & 2 \\
Particle size $(\mu \mathrm{m})$ & $\mathrm{D} 90$ & 69 & 15 \\
& & & 31 \\
\hline
\end{tabular}




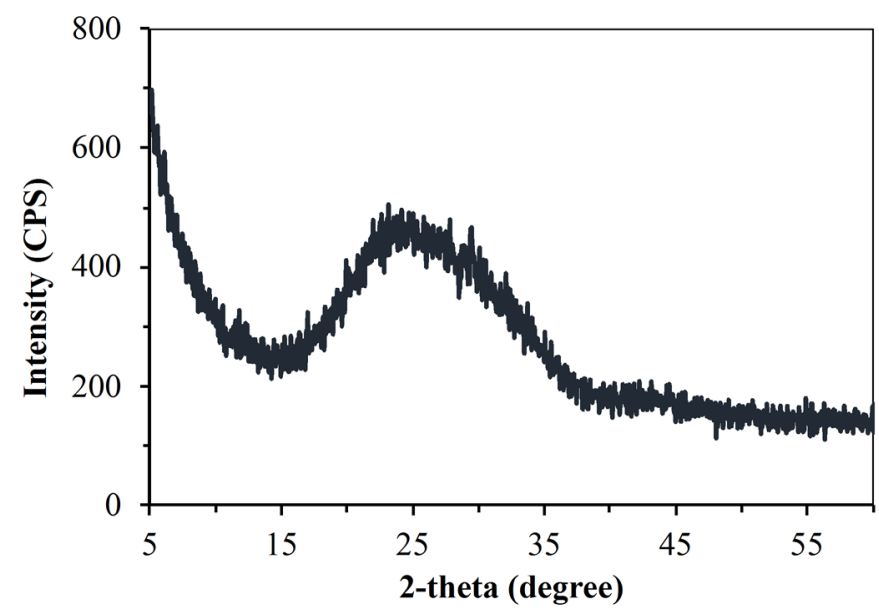

(a)
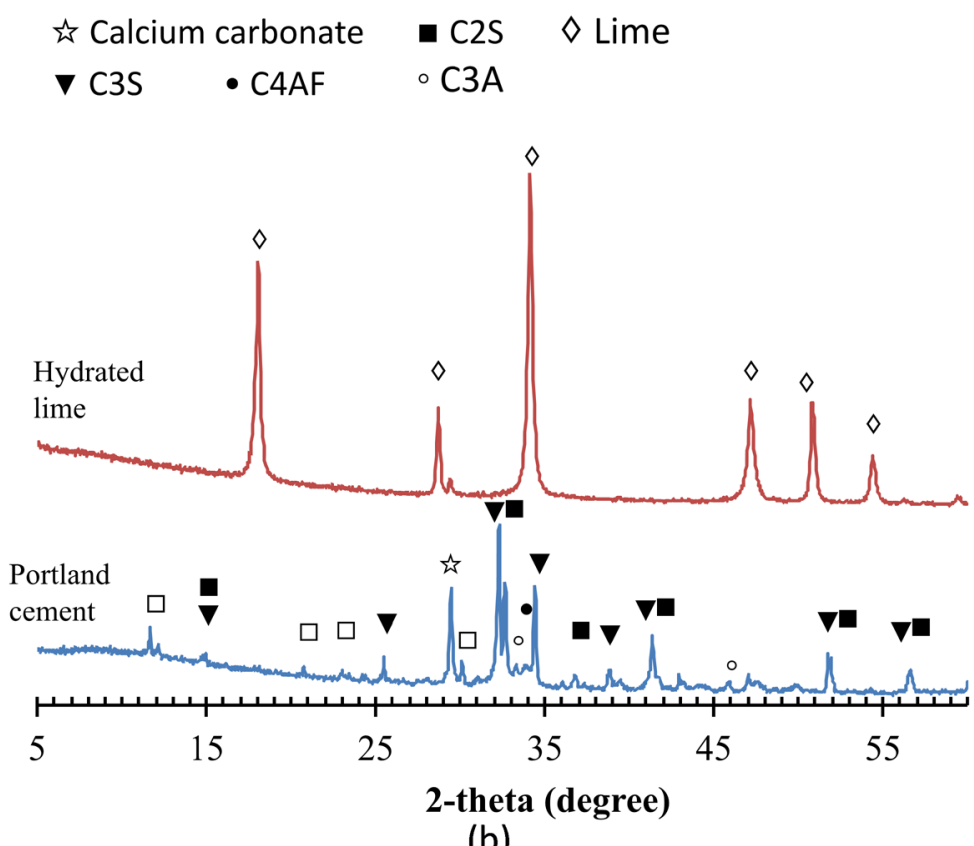

(b)

Figure 1. XRD patterns of raw materials: (a) GP, (b) OPC and hydrated lime.

Hydrated lime, $\left(\mathrm{Ca}(\mathrm{OH})_{2}\right)$ (purity of $92 \%$ ) with $8 \% \mathrm{CaCO}_{3}$ content (characterized by TGA) commercialized by Anachemia is also utilized. Its limit of solubility is $1.73 \mathrm{~g} / \mathrm{l}$ at $20^{\circ} \mathrm{C}$.

The physico-chemical and mineralogical properties of the different used materials are provided in Table 1 and Table 2 and Figure 1.

\subsection{Specimen Preparation}

\section{1) Paste mixture}

Pure cement pastes (labelled OPC) and cement pastes containing $20 \mathrm{wt} \%$ of glass powder (identified 20GP-OPC) with a water-to-binder ratio $(w / b$, binder $=$ $\mathrm{OPC}+\mathrm{GP}$ ) of 0.4 , have been carried out. At the same time, mixtures of $30 \mathrm{wt} \%$ of hydrated lime and 70 wt $\%$ GP (labelled 70GP-L) with w/b of $0.7(b=\mathrm{GP}+L)$ 
Table 2. Chemical composition of OPC and GP (wt\%).

\begin{tabular}{ccccccccccc}
\hline & \multicolumn{10}{c}{ Chemical composition } \\
\cline { 2 - 10 } Materials & $\mathrm{SiO}_{2}$ & $\mathrm{Al}_{2} \mathrm{O}_{3}$ & $\mathrm{Fe}_{2} \mathrm{O}_{3}$ & $\mathrm{MgO}$ & $\mathrm{CaO}$ & $\mathrm{Na}_{2} \mathrm{O}$ & $\mathrm{K}_{2} \mathrm{O}$ & $\mathrm{SO}_{3}$ & LOI & $\mathrm{Na}_{2} \mathrm{O}_{\text {eq }}$ \\
\hline GP & 72.38 & 1.57 & 0.35 & 0.98 & 11.10 & 12.89 & 0.61 & 0.03 & 0.08 & 13.29 \\
OPC & 20.43 & 4.7 & 2.92 & 1.81 & 62.39 & 0.18 & 0.95 & 0.95 & 3.53 & 0.81 \\
\hline
\end{tabular}

determined according to the paste fluidity are also prepared. To avoid the carbonation during mixing, the latter was made under inert atmosphere in a glove bag supplied by a nitrogen gas. Samples were kept inside the globe bag until the various considered deadline. Thermal (TGA-DSC) and structural (XRD) analyses are performed at 1, 28,91, 180 and 365 days in order to follow the evolution of the hydration reaction. The different studied paste formulations are gathered in Table 3.

\section{2) Mortar mixture}

Two mixtures of mortars, the reference (100\% OPC) and cement containing $20 \%$ GP, were prepared with w/b of 0.485 according to ASTM C305. Samples were cured at room temperature and $100 \%$ relative humidity in a saturated lime solution until the measurement of their compressive strength at $1,7,28$, and 91 days.

\subsection{Methods}

The chemical analysis of raw materials was performed through X-ray fluorescence spectrometry by means of PANalytical WD-XRF type apparatus. Pellets containing a mixture of $6.3 \mathrm{~g}$ of the powdered sample and $0.7 \mathrm{~g}$ of a Licowax binder were manually pressed at 25,000 psi.

Structural analysis of raw materials and pastes has been performed through $\mathrm{X}$-ray diffraction using a X'pert Pro MRD type diffractometer provided by PANalytical company in CuKa configuration. Data recorded between $5^{\circ}$ and $60^{\circ}$, were treated using JADE 2010 software for peak identification.

Particle size distribution of GP and OPC was done by means of a Mastersizer 2000 Laser granulometer from Malvern company. To avoid cement hydration during granulometric analysis, the characterization was performed in alcohol (ethanol) medium. The fineness and the density of the used materials were assessed by means of a Blaine permeability and a helium pycnometer respectively. The combined water and lime content in the previously dried and ground pastes are determined using a simultaneous thermogravimetric analysis (TGA)/DSC) (TA Instruments SDT Q600). The paste was subjected to a temperature rise from $50^{\circ} \mathrm{C}$ to $1000^{\circ} \mathrm{C}$ with a speed of $10^{\circ} \mathrm{C} / \mathrm{min}$ under nitrogen flow rate of 100 $\mathrm{ml} / \mathrm{min}$.

- The dehydration of the lime is observed at temperatures ranging from $400^{\circ} \mathrm{C}$ to $450^{\circ} \mathrm{C}$ according to reaction (1):

$$
\mathrm{Ca}(\mathrm{OH})_{2} \rightarrow \mathrm{CaO}+\mathrm{H}_{2} \mathrm{O}
$$


Table 3. Mix proportion of studied pastes.

\begin{tabular}{cccc}
\hline \multirow{2}{*}{ Materials } & \multicolumn{3}{c}{ Mix proportion } \\
\cline { 2 - 4 } & Control & 20GP-OPC & 70GP-L \\
\hline Cement $(\mathrm{g})$ & 500 & 400 & 0 \\
Glass powder $(\mathrm{g})$ & 0 & 100 & 70 \\
Hydrated lime $(\mathrm{g})$ & 0 & 0 & 30 \\
Water $(\mathrm{g})$ & 200 & 200 & 70 \\
\hline
\end{tabular}

- The decomposition of the calcium carbonate resulted from the lime carbonation is observed between $450^{\circ} \mathrm{C}$ and $750^{\circ} \mathrm{C}$ according to reaction (2):

$$
\mathrm{CaCO}_{3} \rightarrow \mathrm{CaO}+\mathrm{CO}_{2}
$$

The weight losses associated with the water departure between $400^{\circ} \mathrm{C}-450^{\circ} \mathrm{C}$ and the release of $\mathrm{CO}_{2}$ between $450^{\circ} \mathrm{C}-750^{\circ} \mathrm{C}$ enable to determine lime, $L(t)$, and carbonated lime, $L_{c c}(t)$, contents at a given time $(t)$ respectively according to equations (3) and (4):

$$
\begin{aligned}
& L(t)=\frac{\Delta m_{400-450^{\circ} \mathrm{C}}}{m_{\text {sample }}} \times \frac{M_{\mathrm{Ca}(\mathrm{OH})_{2}}}{M_{\mathrm{H}_{2} \mathrm{O}}} \\
& L_{c c}(t)=\frac{\Delta m_{450-750^{\circ} \mathrm{C}}}{m_{\text {sample }}} \times \frac{M_{\mathrm{Ca}(\mathrm{OH})_{2}}}{M_{\mathrm{CO}_{2}}}
\end{aligned}
$$

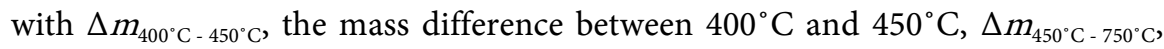
the masse difference between $450^{\circ} \mathrm{C}$ and $750^{\circ} \mathrm{C}, m_{\text {sample }}$, the initial weight of sample and $M_{\mathrm{Ca}(\mathrm{OH})_{2}}, M_{\mathrm{CO}_{2}}$ and $M_{\mathrm{H}_{2} \mathrm{O}}$, the molar masses of $\mathrm{Ca}(\mathrm{OH})_{2}, \mathrm{CO}_{2}$ and $\mathrm{H}_{2} \mathrm{O}$ respectively.

The flow of mortar specimens was measured in accordance with ASTM C1437. The diameter of the specimen after the test was determined according to ASTM C 230. The flow was the resulting average diameter recorded to the nearest millimeter. The compressive strength tests were conducted on $50 \times 50 \times 50$ $\mathrm{mm}$ cubes in line with ASTM C109. A total of three specimens, in each case, were characterized and the average value of the compressive strength nearest 0.1 MPa was determined.

The normal consistency of the studied mortars was obtained according to ASTM C187. The amount of water required for normal consistency was calculated to the nearest $0.1 \%$. A total of three measurements were performed and the resulting average of normal consistency was determined. The initial and final setting times were measured according to the procedure specified in ASTM C191 on paste mixtures proportioned and mixed to normal consistency. The setting time was determined to the nearest $1 \mathrm{~min}$. Two measurements were conducted for each mortar and the average setting time was calculated.

\section{Results and Discussion}

\subsection{Reactivity of GP in the Presence of OPC}

1) $X$-ray diffraction characterization 
Figure 2 shows the variation of XRD patterns during the hydration of both pure cement and the one containing $20 \mathrm{wt} \% \mathrm{GP}$ for various periods. A decrease in peak characteristic of $\mathrm{C}_{3} \mathrm{~S}, \mathrm{C}_{2} \mathrm{~S}, \mathrm{C}_{3} \mathrm{~A}$ and gypsum, present in anhydrous cement is observed for hydrated compound. This decrease is related to the formation of hydration products such as portlandite or lime $(L)$, ettringite (Aft) and calcium silicate hydrate $(\mathrm{CSH})$ from the first day of the cement hydration. The peaks attributed to CSH are less resolved due to its amorphous character. The cement paste containing GP shows the same spectra as those of pure cement paste whatever the curing time. These observations suggest that the presence of

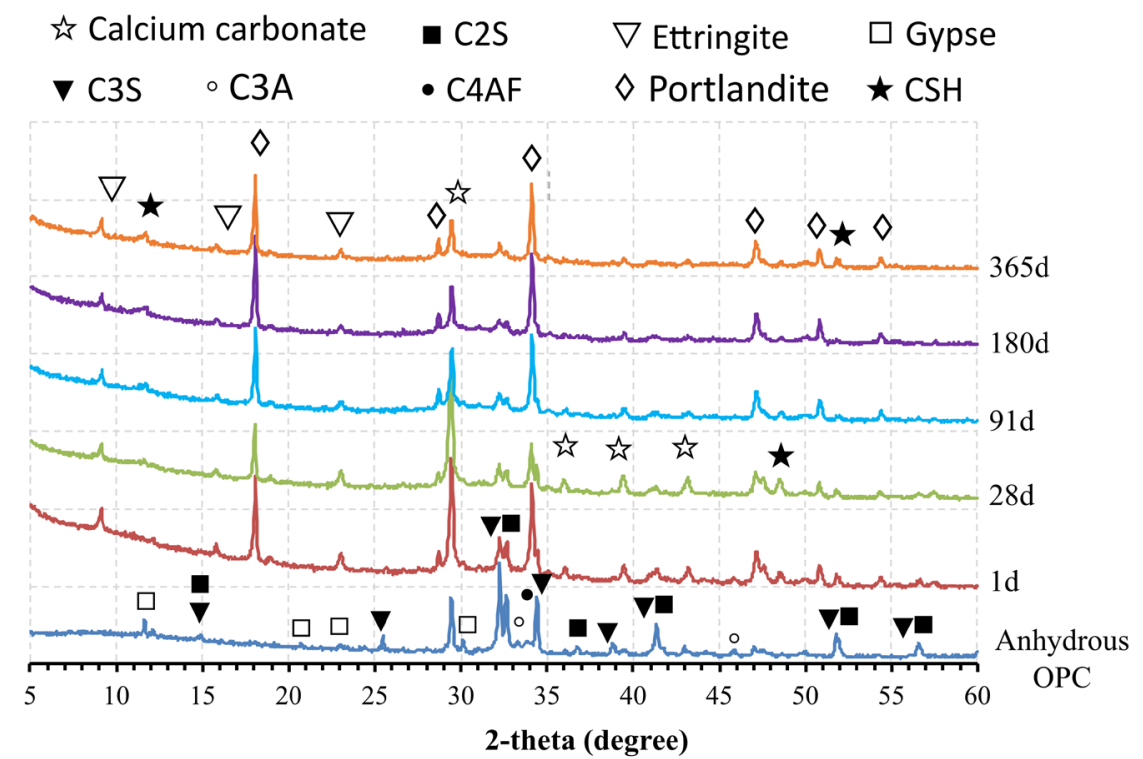

(a)

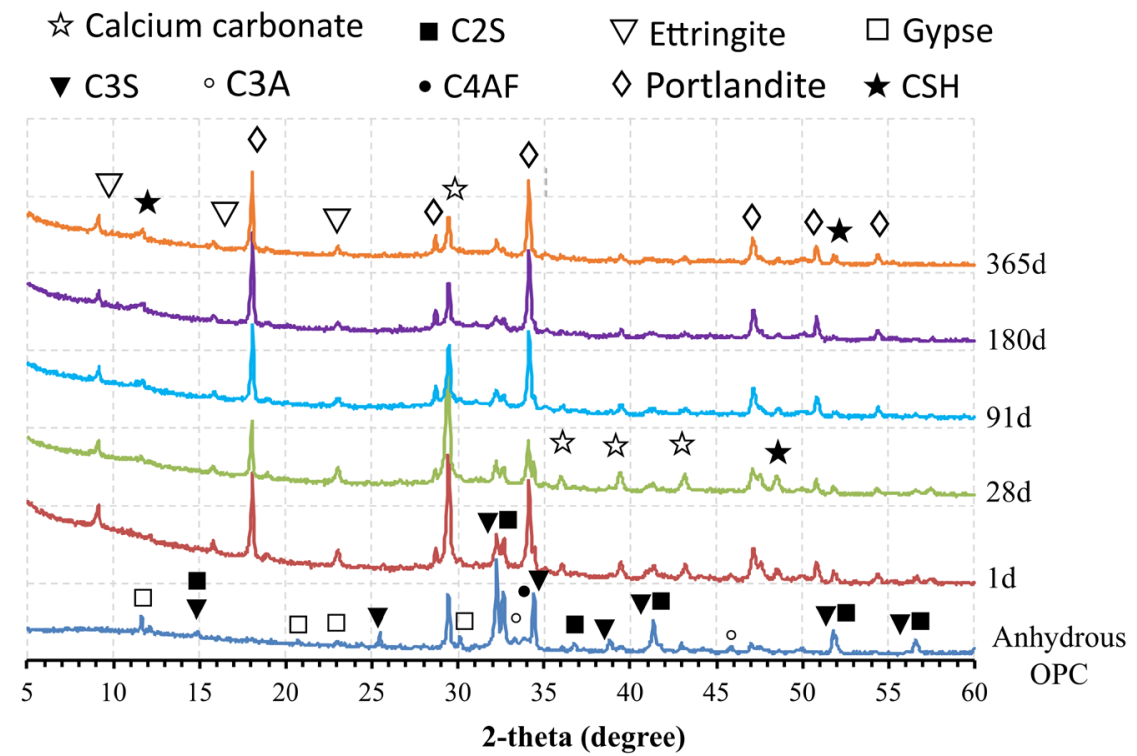

(b)

Figure 2. XRD diffraction patterns of cement pastes at different hydration time: (a) without GP, (b) with $20 \mathrm{wt} \% \mathrm{GP}$. 
GP does not impede the cement hydration. However, since the analysis in this study is only qualitative, it is difficult to isolate the role of GP in the cement hydration process. Otherwise, studies carried out on GP reactivity in an aqueous medium have revealed that because of its amorphous character, the glass powder hydrates very well [17]. This hydration would be favored by the dissolution of the surface alkalis making the medium basic $(\mathrm{pH}>11)$. In addition, it has been shown that the degree of this hydration increased with the contact time of GP with water. Likewise, other authors [1] have shown that an increase in $\mathrm{pH}$ and temperature of the medium accelerated GP hydration reaction. The cement hydration is an exothermic reaction with the release of portlandite which renders the medium more basic, promoting thus GP hydration.

\section{2) Thermal analysis}

Thermogravimetric analysis, TGA, enabled to follow the evolution of the portlandite amount during the cement hydration in the presence of GP. Results are depicted in Figure 3. Analyses were performed at periods of time range from 0 to 365 days ( 0 corresponding to the moment the different components were put into contact). The lime content increases with hydration time regardless of the mixture. The presence of GP leads to a decrease in the amount of lime compared to that in the cement paste. This results from the dilution effect (replacement of part of the cement by GP) on the one hand and from the pozzolanic reaction of GP with lime on the other hand. In the 100\% OPC mixture, a significant increase in the lime content is observed during the first 180 days. Between 180 and 365 days, this content remains almost stationary due to a hydration downturn. In fact, the hydrate layer which coats cement grains gradually becomes thick inducing the decrease in ions and water diffusion towards the anhydrous components of the system. Hydration slowdowns more and more, but can continue for months or even years [18]. Also, unlike $\mathrm{C}_{3} \mathrm{~S}$ which has a fairly rapid hydration

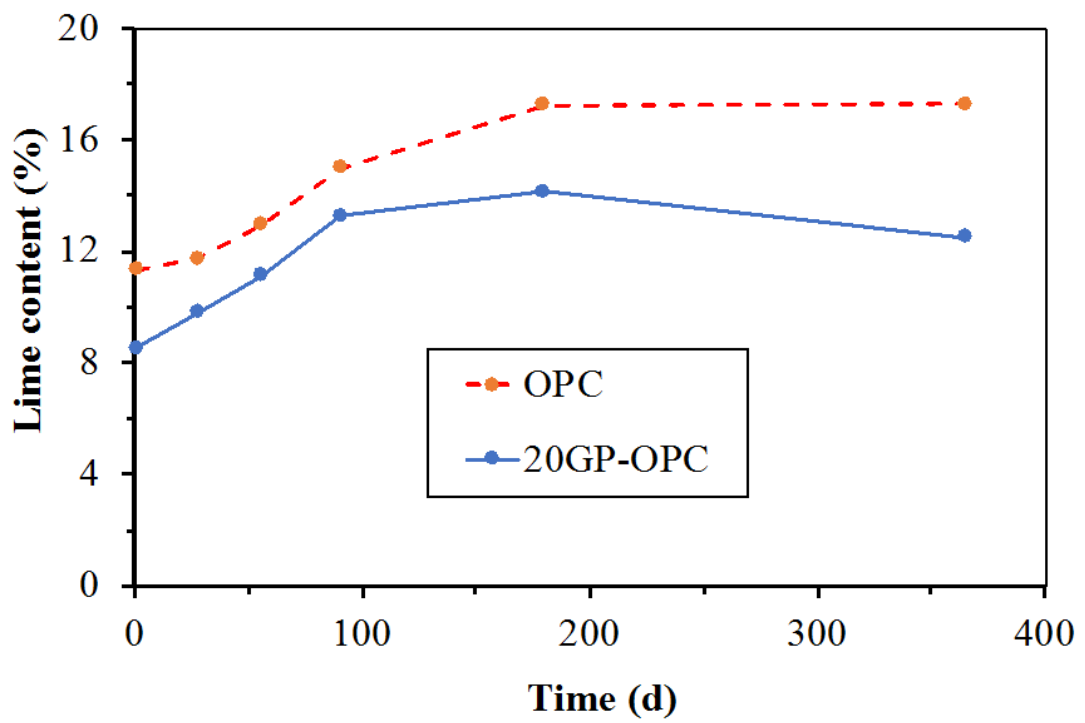

Figure 3. Evolution of lime content in cement pastes over time with $20 \mathrm{wt} \% \mathrm{GP}$ (20GPOPC) and without GP (OPC). 
speed at a young age, $\mathrm{C}_{2} \mathrm{~S}$ that intervenes at more advanced ages hydrates very slowly.

For the paste containing GP, a significant increase in lime content is observed the first 91 days followed by a low increase between 91 and 180 days. From 180 to 365 days, a decrease in the lime content is observed. These observations suggest that the hydration reaction of cement outweighs the pozzolanic reaction of glass powder with lime in the first 91 days. From 91 to 180 days, the effect of the cement hydration is less marked suggesting an acceleration of the pozzolanic reaction. This pozzolanic reaction becomes preponderant from 180 to 365 days. This insinuates that from 91 days, the pozzolanic reaction would prevail over the cement hydration. The pozzolanic reaction only begins when there is enough lime in the medium. This result is in accordance with that observed by other researchers [11] [12] who showed that the beneficial effects of the pozzolanic reaction in cementitious systems are noticeable from curing time greater than or equal to 56 days.

\subsection{Hydration of GP in the Presence of Hydrated Lime}

\section{1) $X$-ray diffraction characterization}

The hydration of GP in the presence of hydrated lime was monitored by XRD over a period of 365 days. Figure 4 shows the X-ray diffraction spectra of samples after 1, 28, 91, 180 and 365 days of reaction. The spectrum of hydrated lime was considered for comparison. The XRD of the sample at 1 and 28 days revealed a high carbonation, probably due to poor conditioning before the analysis. This results in a predominance of peak characteristic of calcium carbonate at the expense of the other elements suggesting a weak pozzolanic reaction. In fact, high carbonation indicates the presence of high content of unreacted lime which



Figure 4. XRD patterns of 70GP-L as a function of hydration duration. $L_{\text {hyd }}$ corresponding to hydrated lime spectrum. 
is likely to carbonate. However, unlike the 28-day sample which seems not to contain any more lime, the 1-day sample is less carbonated because it still contains lime, according to XRD analysis. These results show the importance of minimizing the contact time of the sample with ambient air before characterization tests when the latter still contains lime. These observations suggest that the pozzolanic reaction would be negligible up to 28 days. This is similar to previous results obtained in a cement system [3] [11] [12].

From 91 days, a decline in the intensity of the peaks of lime as a function of time, is observed. This decrease is accompanied by the appearance of peaks of $\mathrm{C}-\mathrm{S}-\mathrm{H}$ that are less resolved due to its amorphous nature. In addition, the quasi absence of calcium carbonate peaks suggests that the lime did not carbonate, thus confirming the reaction of GP with the lime, namely the pozzolanic reaction. The disappearance of peaks attributed to lime and carbonate at 365 days indicates an almost total pozzolanic reaction, confirmed by the unique presence of CSH peaks. The pozzolanic reaction is therefore a slow reaction which appears to be better revealed beyond a sufficiently long time ( $t>28$ days) when GP is put into contact with lime in aqueous media. It emerges from these observations that the more time the sample spends in a controlled atmosphere, the less it is subject to carbonation because of the pozzolanic reaction which is raised. Carbonation, therefore, seems to take place after putting out the sample when it still contains lime (as in the case of 1 and 28 days) and this, during the preparation for the various characterization tests, hence the importance of taking precautions to minimize carbonation as previously outlined.

\section{2) Thermal analysis}

Figure 5 shows the evolution from 0 to 365 days of the lime content characterized by the TGA thermal analysis of 70GP-L mixture. According to XRD results, carbonation takes place outside when the sample comes into contact with atmosphere. The remaining lime content $\left(L_{\text {residual }}\right)$ determined is therefore the sum of lime $(L)$ content in the sample during the analysis (determined according to relation (3)) and that carbonated, $L_{c o}$ (determined according to relation (4)) at a given time $(t)$.

$$
\begin{aligned}
& L(t)=\left[\frac{\Delta m_{400-450^{\circ} \mathrm{C}}}{m_{\text {sample }}} \times \frac{M_{\mathrm{Ca}(\mathrm{OH})_{2}}}{M_{\mathrm{H}_{2} \mathrm{O}}}\right] \frac{100}{27.546} \\
& L_{c c}(t)=\left[\frac{m_{450-750^{\circ} \mathrm{C}}}{m_{\text {sample }}} \times \frac{M_{\mathrm{Ca}(\mathrm{OH})_{2}}}{M_{\mathrm{CO}_{2}}}\right] \frac{100}{27.546}
\end{aligned}
$$

This results in the relation (5):

$$
L_{\text {residual }}(t)=\left[\left(\frac{m_{400-450^{\circ} \mathrm{C}}}{m_{\text {sample }}} \times \frac{M_{\mathrm{Ca}(\mathrm{OH})_{2}}}{M_{\mathrm{H}_{2} \mathrm{O}}}\right)+\left(\frac{m_{450-750^{\circ} \mathrm{C}}}{m_{\text {sample }}} \times \frac{M_{\mathrm{Ca}(\mathrm{OH})_{2}}}{M_{\mathrm{CO}_{2}}}\right)\right] \frac{100}{27.546}
$$

with $27.546 \mathrm{~g}$ corresponding to the total amount of pure lime in the mixture.

The consumed lime $\left(L_{\text {reacted }}\right)$ represents the lime content which has reacted with the glass powder. It corresponds to the difference between the initial lime 


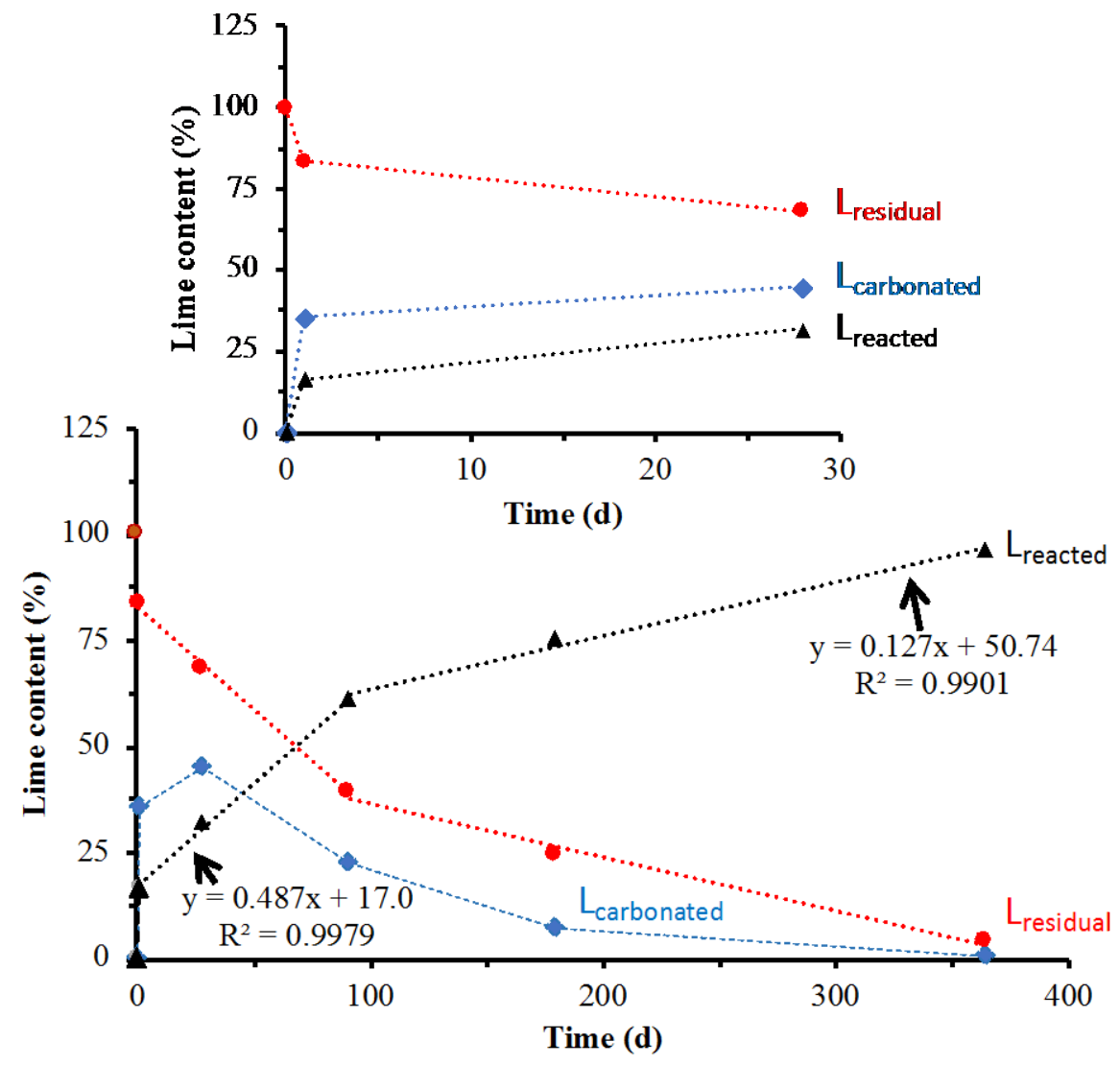

Figure 5. Variation of lime content (\%) during the pozzolanic reaction of GP, with a zoom on the evolution between 0 and 28 days above.

content before mixing and the remaining lime content according to the relation (6):

$$
L_{\text {reacted }}(t)=100 \%-L_{\text {residual }}
$$

A gradual decrease in the lime content in the paste is observed over time. At 1 , 28, 91, 180 and 365 days after mixing, the amount of lime in the paste passes from $100 \%$ to $83.34 \%$; $68.23 \%$; $39.09 \%$; $24.44 \%$ and $3.66 \%$ respectively. This represents a decrease of $16.66 \% ; 31.77 \%$; $60.91 \%$; $75.56 \%$ and $96.34 \%$ corresponding to the lime consumed by the pozzolanic reaction at these different periods. Also, one can note that more than half of the lime (60.91\%) is consumed after 91 days and almost all (96.34\%) after 365 days of reaction. These results are in line with those previously obtained with XRD analysis which revealed the presence of peaks of C-S-H to the detriment of lime and calcium carbonate as a function of time (Figure 4). However, TGA reveals that the pozzolanic reaction starts right within 24 hours after mixing, with $16.7 \%$ of lime which has reacted. The rise in the amount of the reacted lime to $31.8 \%$ after 28 days shows an increase in the pozzolanic activity.

Moreover, there is a significant carbonation of $35.65 \%$ from the first day which increases to $44.9 \%$ at 28 days. It is therefore obvious that it was the high carbonation of the sample at 1 and 28 days that inhibited the detection of the less 
resolved peaks of $\mathrm{CSH}$ in XRD. However, carbonation gradually decreases from 91 days to almost zero $(0.37 \%)$ at 365 days of reaction. These results are well in line with those observed in XRD which showed a high carbonation at 1 and 28 days and a low carbonation for older ages. Accordingly, carbonation is linked to the presence of a high quantity of vulnerable element such as lime in the mixture. The longer the sample is maintained in a controlled atmosphere, the more the lime present reacts and the less the sample is exposed to carbonation.

Also, unlike the almost non-existent or hardly detectable pozzolanic activity at young age in a cementitious medium, a GP reaction is observed as early as 24 hours when the latter is brought directly into contact with lime. This suggests that in the presence of cement, the observed delay in GP pozzolanic reaction could be due to both the low availability of the portlandite and the predominance of the cement hydration reaction. Indeed, studies showed that in cement-based materials, the beneficial effects of the pozzolanic reaction of cementitious additions, especially GP, on the physico-chemical properties of the material can only be detected after 56 days of reaction [12].

The pozzolanic reaction of glass powder with lime can be subdivided into three distinct stages: from 0 to 1 day, from 1 to 91 days and from 91 to 365 days. Figure 6 shows the evolution of the different lime contents during the defined periods. Thus, over the period of 1 day (24 hours), $16.7 \%$ of the lime reacted with GP to form CSH. However, there is a significant carbonation of $35.7 \%$. From 1 to 91 days, $44.3 \%$ of lime reacted with GP with a significant reduction in carbonation. From 91 to 365 days, 35.4\% of lime reacted bringing to a total of 96.4\% of lime which reacted to form CSH over the total reaction time with a negligible carbonation. These results are consistent with those obtained by X-ray diffraction for the sample at 365 days which reveals the major presence of $\mathrm{CSH}$ and the quasi absence of calcium carbonate.

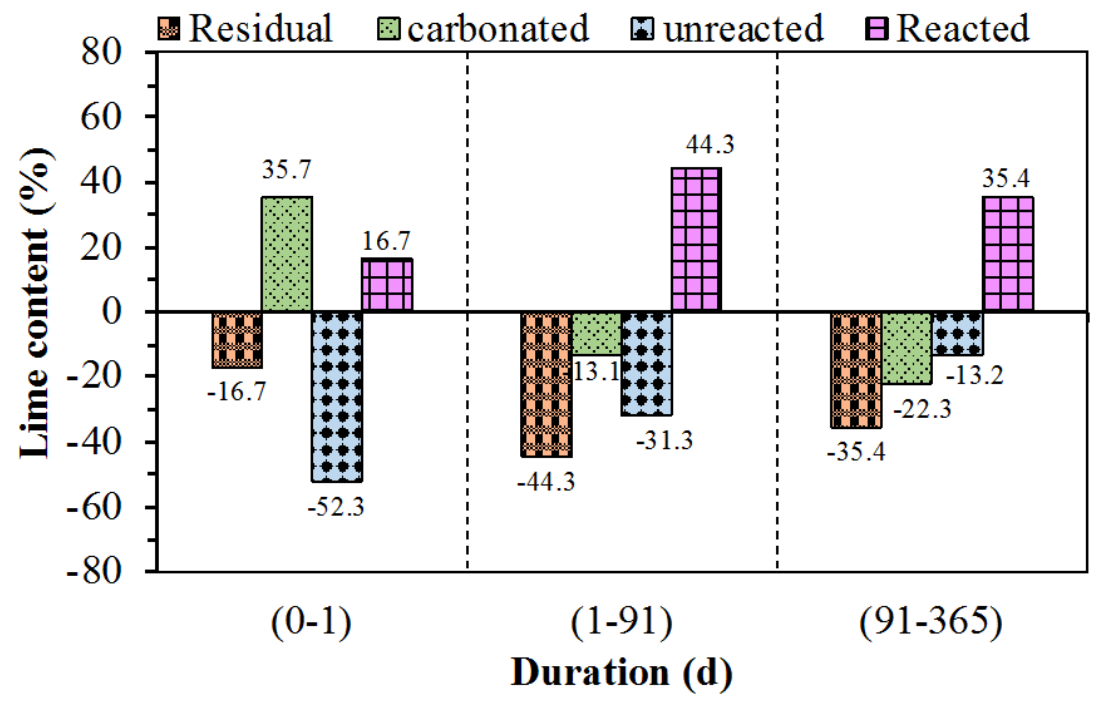

Figure 6. Remaining, carbonated, unreacted and reacted lime contents for the different defined hydration periods. 


\subsection{Mortar Characterization}

Table 4 shows the flow, setting time and water demand of mortars containing $20 \%$ GP in comparison with the reference (without GP). According to these results, the presence of GP in cement mortar slightly decreases the flow. The water demand was similar in both cases, since the normal consistency of paste was $29.7 \%$ regardless of the paste considered. For the setting time, the reference paste began setting $7 \mathrm{~min}$ before the GP-based paste and recorded the longest final setting time. These results suggest that the setting time is shortened by replacing a part of the cement with the glass powder. This could be due to the alkali ions, which are known to speed up the reaction mechanism [19].

Changes in the compressive strength were also assessed as a function of curing time. The results reported in Table 4 show an increase in the compressive strength over time regardless of the mortar type, expressing the normal progression of the hydration process. However, the compressive strength of GP-based mortar was lower than the one of the control. This is due to the well-known dilution effect, as a part of the more reactive product, namely the cement, was replaced by GP. Besides, the pozzolanic activity of GP was well illustrated through the pozzolanic index determined from the compressive strength of mortars (Table 4). One can observe a clear increase in the pozzolanic index of GP with the time highlighting the consumption of the portlandite resulting from cement hydration by GP. After 91 days of reaction, both the reference and GP mortar possessed similar compressive strength of about $41 \mathrm{MPa}$ confirming the effectiveness of GP as a pozzolanic material. All these observations are consistent with results obtained with XRD and TGA on the studied pastes.

\subsection{Pozzolanic Reaction Mechanism}

The analyzes carried out on the 70GP-L paste revealed a progressive consumption of lime by GP. Thus, the evolution of the pozzolanic reaction of the glass powder in the presence of hydrated lime can be described in three stages as follows:

Table 4. Fresh and hardened properties of studied mortars.

\begin{tabular}{|c|c|c|c|c|}
\hline \multicolumn{5}{|c|}{ Fresh properties } \\
\hline Parameters & Time (days) & Control & $20 \mathrm{GP}$ & Pozzolanic index (\%) \\
\hline Flow $(\mathrm{mm})$ & & $225 \pm 2$ & $180 \pm 0$ & \\
\hline Initial setting ( $\min )$ & & $212 \pm 2$ & $203 \pm 2$ & \\
\hline Final setting (min) & & $247 \pm 1$ & $238 \pm 1$ & \\
\hline Water demand (5) & & $29.7 \pm 3$ & $29.6 \pm 0.1$ & \\
\hline \multicolumn{5}{|c|}{ Hardened properties } \\
\hline \multirow{4}{*}{$\begin{array}{l}\text { Compressive strength } \\
\qquad(\mathrm{MPa})\end{array}$} & 1 & $13.6 \pm 0.6$ & $8.8 \pm 0.5$ & 64.7 \\
\hline & 7 & $33.3 \pm 0.1$ & $25.5 \pm 0.3$ & 76.6 \\
\hline & 28 & $40.8 \pm 0.1$ & $36.39 \pm 0.0$ & 89.2 \\
\hline & 91 & $41.9 \pm 1.8$ & $41.1 \pm 0.9$ & 98.1 \\
\hline
\end{tabular}


- Dissociation of lime in the presence of water according to Equation (7).

$$
\mathrm{Ca}(\mathrm{OH})_{2} \rightarrow \mathrm{Ca}^{2+}+2 \mathrm{OH}^{-}
$$

- The presence of $\mathrm{OH}^{-}$ions in solution leads to a strongly basic medium ( $\mathrm{pH}>$ 12) promoting the partial dissolution of the amorphous silica of GP and thus the dissolution of silicates following the reaction (8).

$$
\mathrm{SiO}_{2}+2 \mathrm{OH}^{-}+\mathrm{H}_{2} \mathrm{O} \rightarrow \mathrm{H}_{2} \mathrm{SiO}_{4}^{2-}
$$

The concentration of dissolved silicates will increase with the amount of water.

- Then, reaction of silicates $\mathrm{H}_{2} \mathrm{SiO}_{4}^{2-}$ with calcium ions $\left(\mathrm{Ca}^{2+}\right)$ to form $\mathrm{CSH}$ according to Equation (9) [20]:

$$
x \mathrm{Ca}^{2+}+\mathrm{H}_{2} \mathrm{SiO}_{4}^{2-}+2(x-1) \mathrm{OH}^{-}+(y-x) \mathrm{H}_{2} \mathrm{O} \rightarrow x \mathrm{CaO} \cdot \mathrm{SiO}_{2} \cdot y \mathrm{H}_{2} \mathrm{O}(\mathrm{C}-\mathrm{S}-\mathrm{H}) \text { (9) }
$$

Therefore, from 0 to 1 day, there is mainly the lime dissociation reaction accompanied by a low dissolution of silicates. This explains the consumption of $16.7 \%$ of lime observed. From 1 to 91 days, the dissolution of silicates is more important, causing the formation of more $\mathrm{CSH}$, hence the high rate of $44.3 \%$ lime consumed. This high consumption of lime is perfectly reflected in its evolution along the line of equation $y=0.4865 x+16.986$ with a coefficient of determination $R^{2}=0.9979$ and a high slope of 0.5 (Figure 5). Subsequently, the decrease in the lime content in the medium will lead to a reduction in soluble silicates and therefore in the amount of $\mathrm{CSH}$ formed; explaining the lower lime amount of $35.4 \%$ which reacts with GP in the period of 91 to 365 days. This is reflected in the curve of the consumed (or reacted) lime content which changes along the line of equation $y=0.1267 x+50.735$ with a coefficient of determination $R^{2}=0.9901$ and a lower slope of 0.13 .

Furthermore, the formation of C-S-H hydrates in a cement paste mainly sums up to the hydration of alite $\left(\mathrm{C}_{3} \mathrm{~S}\right)$ at younger ages and the one of belite $\left(\mathrm{C}_{2} \mathrm{~S}\right)$ at advanced ages according to the following reactions (10) and (11):

$$
2\left(3 \mathrm{CaO} \cdot \mathrm{SiO}_{2}\right)+6 \mathrm{H}_{2} \mathrm{O} \rightarrow 3 \mathrm{CaO} \cdot 2 \mathrm{SiO}_{2} \cdot 3 \mathrm{H}_{2} \mathrm{O}+3 \mathrm{Ca}(\mathrm{OH})_{2}
$$

Or $2 \mathrm{C}_{3} \mathrm{~S}+6 \mathrm{H} \rightarrow \mathrm{C}-\mathrm{S}-\mathrm{H}+3 \mathrm{CH}$

$$
2\left(2 \mathrm{CaO} \cdot \mathrm{SiO}_{2}\right)+4 \mathrm{H}_{2} \mathrm{O} \rightarrow 3 \mathrm{CaO} \cdot 2 \mathrm{SiO}_{2} \cdot 3 \mathrm{H}_{2} \mathrm{O}+\mathrm{Ca}(\mathrm{OH})_{2}
$$

Or $2 \mathrm{C}_{2} \mathrm{~S}+6 \mathrm{H} \rightarrow \mathrm{C}-\mathrm{S}-\mathrm{H}+3 \mathrm{CH}$

In the cement paste containing GP, the lime or portlandite $\left(\mathrm{Ca}(\mathrm{OH})_{2}\right)$ formed during the hydration of $\mathrm{C}_{3} \mathrm{~S}$ and $\mathrm{C}_{2} \mathrm{~S}$ will make the medium more basic $(\mathrm{pH}>$ 12) due to the presence of $\mathrm{OH}^{-}$ions in the interstitial solution. Also, the dissolution of alkali ions present on the glass surface will significantly increase the $\mathrm{pH}$ of the system. In fact, it has been demonstrated that in aqueous medium, alkalis on GP surface readily pass into the solution resulting in the $\mathrm{pH}$ enhancement [17] [19]. This basic medium associated with the increase of the temperature due to the exothermic reaction of the cement hydration fosters the partial dissolution of amorphous silica of GP according to reaction (8). Then, soluble silicates will 
react with calcium ions following the reaction (9) to form supplementary C-S-H.

Moreover, in cementitious system, the GP pozzolanic reaction would take place after the beginning of the cement hydration when enough lime will be available to favor the dissolution of GP silicates. Thereafter the two reactions would take place simultaneously with a predominance of one over the other depending on the reaction time. Although the pozzolanic reaction would start at young age, it would not be perceptible before 91 days (in line with the results obtained on the studied mortars), owing to the continuous production of $\mathrm{Ca}(\mathrm{OH})_{2}$ by the cement hydration contrary to what is observed in the mixture without cement (70GP-L). Indeed, the fixed level of $\mathrm{Ca}(\mathrm{OH})_{2}$, in the paste 70GP-L (without cement), enables to detect earlier the effects of the pozzolanic reaction of GP. However, when this rate is constantly increasing (as in the case of 20GP-OPC), its consumption is difficult to assess because of the predominance of the hydration reaction. This leads to an increase in its content in the reactive medium despite the pozzolanic reaction. At advanced ages, especially from 91 days, the pozzolanic reaction of the glass powder is clearly noticeable with a decrease of the lime content in the medium. These observations are confirmed by the compressive strength value of the mortar containing GP which is equivalent to that of the control at 91 days (Table 4).

All these results reveal that in a cementitious environment, the presence of pozzolanic material such as GP would cause competition between the cement hydration and the GP pozzolanic reaction. At young age, the cement hydration would prevail over the pozzolanic reaction resulting in a decrease in the physico-chemical and mechanical properties of the material due to the dilution effect. Afterward, at advanced ages, especially from 91 days, the predominance of the pozzolanic reaction would lead to the formation of additional C-S-H, which would contribute to improve the material properties. These results are well in line with those observed on the evolution of the mechanical properties of concrete incorporating GP. Studies have shown that at early age, the presence of GP induces a reduction in the compressive strength of concrete [12]. In contrast, from 56 days, an increase in the compressive strength of such a concrete to reach the one of the control concrete (100\% OCP) was observed. At advanced ages (from 91 or 180 days), depending on the water-to-binder ratio, the concrete containing GP exhibited higher resistance than that of the control concrete [12].

\section{Conclusions}

The reactivity of the glass powder with lime was analyzed in mixtures of cement pastes containing $0 \%$ and $20 \%$ GP and pastes of $70 \%$ GP and $30 \%$ lime. The monitoring of the paste hydration carried out by means of XRD and TGA-DSC enables to show a progressive increase in portlandite content in cement pastes containing or not GP. But the amount of the portlandite in the GP-based cement paste was always lower due on the one hand to the dilution effect and on the other hand to the pozzolanic reaction which consumes the portlandite. The ce- 
ment hydration and the GP pozzolanic reaction co-existed from the first days after mixing with a predominance of the first over the second up to 91 days. Beyond this period, the pozzolanic reaction would outweigh the cement hydration with a gradual decrease in the lime content in the paste. These observations were confirmed by the results obtained from the characterization of the glass powder-lime paste mixture. The consumption of about $17 \%$ of the lime by GP was detected as early as 24 hours after mixing. This amount reached more than $60 \%$ after 91 days with almost all of the lime (96\%) consumed 365 days after mixing. The predominance of the pozzolanic reaction results in the formation of a significant amount of supplementary C-S-H in the long term contributing to the improvement of the mechanical properties of the material.

All these results have demonstrated the effectiveness of the pozzolanic properties of glass powder in building materials.

\section{Acknowledgements}

The authors gratefully acknowledge the financial support of the Fonds de recherche du Québec-Nature et technologies (FRQNT) and the Industrial Chair Glass recycling in Materials provided by the Société des Alcools du Québec (SAQ).

\section{Conflicts of Interest}

The authors declare no conflicts of interest regarding the publication of this paper.

\section{References}

[1] Idir, R., Cyr, M. and Tagnit-Hamou, A. (2013) Role of the Nature of Reaction Products in the Differing Behaviours of Fine Glass Powders and Coarse Glass Aggregates Used in Concrete. Materials and Structures, 46, 233-243. https://doi.org/10.1617/s11527-012-9897-z

[2] Tagnit-Hamou, A. and Tognonvi, M.T. (2015) Utilization of Locally Available Industrial and Agro-Industrial Wastes in Concrete: A Sustainable Solution. Journal of the Chinese Ceramic Society, 43, 1372-1384.

[3] Zidol, A., Tognonvi, T.M. and Tagnit-Hamou, A. (2013) Advances in Durable Concrete Materials Applied to the African Context. 1 st International Conference on Advances in Cement and Concrete Technology in Africa, Johannesburg, 611-618.

[4] Ogundairo, T.O., Adegoke, D.D., Akinwumi, I.I. and Olofinnade, O.M. (2019) Sustainable Use of Recycled Waste Glass as an Alternative Material for Building Construction-A Review. IOP Conference Series: Materials Science and Engineering, 640, Article ID: 012073. https://doi.org/10.1088/1757-899X/640/1/012073

[5] Kateb, M.L. (2009) Utilisation des granulats de verre dans la fabrication des bétons architecturaux \& quot; cas des briques en bétons \& quot. Université de Sherbrooke, Sherbrooke.

[6] Tittarelli, F., Giosuè, C. and Mobili, A. (2018) Recycled Glass as Aggregate for Architectural Mortars. International Journal of Concrete Structures and Materials, 12 , 57. https://doi.org/10.1186/s40069-018-0290-3 
[7] Bisht, K. and Ramana, P.V. (2018) Sustainable Production of Concrete Containing Discarded Beverage Glass as Fine Aggregate. Construction and Building Materials, 177, 116-124. https://doi.org/10.1016/j.conbuildmat.2018.05.119

[8] Shayan, A. and Xu, A. (2004) Value-Added Utilisation of Waste Glass in Concrete. Cement and Concrete Research, 34, 81-89. https://doi.org/10.1016/S0008-8846(03)00251-5

[9] Idir, R., Cyr, M. and Tagnit-Hamou, A. (2011) Pozzolanic Properties of Fine and Coarse Color-Mixed Glass Cullet. Cement and Concrete Composites, 33, 19-29. https://doi.org/10.1016/j.cemconcomp.2010.09.013

[10] Shayan, A. and Xu, A. (2006) Performance of Glass Powder as a Pozzolanic Material in Concrete: A Field Trial on Concrete Slabs. Cement and Concrete Research, 36, 457-468. https://doi.org/10.1016/j.cemconres.2005.12.012

[11] Idir, R. (2009) Mécanismes d'action des fines et des granulats de verre sur la réaction alcali-silice et la réaction pouzzolanique. INSA, Toulouse. https://www.theses.fr/2009ISAT0029

[12] Zidol, A. (2014) Durabilité en milieux agressifs des bétons incorporant la poudre de verre.

[13] Zidol, A., Tognonvi, M.T. and Tagnit-Hamou, A. (2017) Effect of Glass Powder on Concrete Sustainability. New Journal of Glass and Ceramics, 7, 34-47. https://doi.org/10.4236/njgc.2017.72004

[14] Odler, I. (2003) Hydration, Setting and Hardening of Portland Cement. In: Hewlett, P.C., Ed., Lea's Chemistry of Cement and Concrete, 4th Edition, Elsevier, Amsterdam, 241-297. https://doi.org/10.1016/B978-075066256-7/50018-7

[15] Aïtcin, P.C. (2015) Phenomenology of Cement Hydration. In: Science and Technology of Concrete Admixtures, Woodhead Publishing, Sawston’, 15-25. https://doi.org/10.1016/B978-0-08-100693-1.00002-3

[16] Liu, L., Yang, P., Qi, C., Zhang, B., Guo, L. and Song, K.-I. (2019) An Experimental Study on the Early-Age Hydration Kinetics of Cemented Paste Backfill. Construction and Building Materials, 212, 283-294. https://doi.org/10.1016/j.conbuildmat.2019.03.322

[17] Tognonvi, M.T., Konan, L.K., Kouassi, S.S., Bi, H., Gouré, I., Zidol, A., Harbec, D. and Tagnit-hamou, A. (2018) Reactivity of Glass Powder in Aqueous Medium. Advanced Materials, 7, 9-14. https://doi.org/10.11648/j.am.20180701.12

[18] Rafaï, N. (2008) Les composantes de la matrice cimentaire: Rappels et interactions, Ciments, betons, platres, chaux. CBPC No. 890-Avril-Mai, 60-66.

[19] Tognonvi, M.T., Zidol, A., Aïtcin, P.-C. and Tagnit-Hamou, A. (2015) Aging of Glass Powder Surface. Journal of Non-Crystalline Solids, 427, 175-183. https://doi.org/10.1016/j.jnoncrysol.2015.07.042

[20] Greenberg, S.A., Chang, T.N. and Anderson, E. (1960) Investigation of Colloidal Hydrated Calcium Silicates. I. Solubility Products. The Journal of Physical Chemistry, 64, 1151-1157. https://doi.org/10.1021/j100838a012 